\title{
Cardiff Acne Disability Index based Quality of Life in Acne Patients, Risk Factors and Associations
}

\author{
Nadia Shams, Furquana Niaz, Sumayya Zeeshan, Sadaf Ahmed, Shazia Farhat, \\ Naresh Kumar Seetlani
}

ABSTRACT

BACKGROUND: Acne Vulgaris is a frequently seen dermatological condition having physical and psychosocial implications. Current study aims to assess Quality of life (QoL) in acne patients and study the associated risk factors.

METHODOLOGY: This descriptive cross sectional study was conducted in 6 months duration at Dept. of Dermatology, Rawal Institute of Health Sciences Islamabad after ethical approval. Total 205 cases of acne (age $>12$ years) were included. Patients with severe systemic illness and endocrine disease were excluded. Global Acne Grading Scale (GAGS) was used to grade acne as mild, moderate or severe. Quality of life assessed by Cardiff Acne disability index (CADI) with outcome as no impairment, mild impairment, moderate impairment or severe impairment. Data analyzed via SPSS version 17 with Chi-square test applied for significance. The $p$-value $<0.05$ considered to be statistically significant.

RESULTS: Among 205 acne cases (24\% males and $76 \%$ females), mean age was $25 \pm 5.7$ (14-36) years. As per GAGS score; mild acne was present in $45.4 \%$, moderate acne $(44 \%)$, severe acne $(8.35 \%)$ and very severe acne (2.4\%). As per CADI score, there was no impairment in $7.3 \%$, mild impairment $(19.5 \%)$, moderate impairment (61\%) and severe impairment in (12\%). The impaired QoL was found to be associated with gender, socioeconomic class, education, acne grade, obesity and use of alternative medicine $(p<0.05)$.

CONCLUSION: Acne vulgaris significantly impairs QoL in adolescents to varying degrees. Higher grade of acne, female gender, obesity, illiteracy and poverty are the proposed risk factors for impaired QoL in acne cases. Early identification of acne cases at risk of impaired Qol may be helpful to take QoL measures like counseling and psychological intervention in parallel with medical management. This may improve the social and psychological wellbeing of acne cases.

Key words: Acne, Cardiff Acne disability index. Global Acne Grading Scale. Quality of life.

This article may be cited as: Shams N, Niaz F, Zeeshan S, Ahmed S, Farhat S, Seetlani NK. Cardiff Acne Disability Index based Quality of Life in Acne Patients, Risk Factors and Associations.

J Liaquat Uni Med Health Sci. 2018;17(01):29-35. doi: 10.22442/jlumhs.181710545

\section{INTRODUCTION}

Acne Vulgaris is a frequently seen dermatological condition in adolescent age group and has physical and psychosocial implications. ${ }^{1}$ Acne is characterized by inflammatory changes in pilo-sebaceous units caused by the bacteria Propioni-bacterium acnes. The global burden of acne is estimated to be $9.4 \%$ and it has been ranked as $8^{\text {th }}$ most prevalent disease all over the world. ${ }^{2}$

Human skin is considered as social organ that acts as an interface for external world interaction ${ }^{3}$. Psychosocial implications of acne include occupational consequences, financial burden, anxiety, anger, social withdrawal, depression and suicidal ideation'., ${ }^{4,5}$ The social, psychological and emotional effects of acne are comparable with certain chronic disease like asthma, epilepsy, diabetes and arthritis. ${ }^{6}$ This indicates that acne shouldn't be considered as minor problem and there is need for appropriate measures to improve QoL in acne patients.

WHO defines quality of life (QoL) as the perception of individual of their position in life in terms of their culture and value systems, in relation to their goals, standards, expectations and concerns. ${ }^{7}$ One of the duties of health care provider is to improve QoL. The Cardiff Acne Disability Index (CADI) is a five item questionnaire to evaluate acne related disability in clinical practice. ${ }^{8}$ Measuring the QOL allows us to understand the patient's perspective of disease. Acne is treatable disease; however it requires long term treatment that improves the QoL. ${ }^{9}$

There have been fewer Pakistani studies addressing QoL in acne. Also there is regional variation in risk factors and associations of Acne. Current study was conducted to determine the impact of acne on QoL using the Cardiff acne disability index (CADI) and to 
study its relationship with severity of acne, also to identify particular risk factors for impaired QoL in acne cases. Results of this study will be helpful to improve Qol in acne patients by addressing these risk factors.

\section{METHODOLOGY}

This descriptive cross sectional study was conducted at Dept. of Dermatology, Rawal Institute of Health Sciences from October 2015 to March 2016 after approval from Rawal Institute Ethical Committee. Current study aims to assess Quality of life (QoL) in acne patients and study the risk factors and associations of impaired QoL. Total 205 cases of acne (age $\geq 12$ years) of both the genders were included from dermatology outdoor clinic after informed consent. Patients having severe systemic illness and endocrine disorders (i.e. hypo or hyperthyroidism, polycystic ovarian females and pregnant women) were excluded. Sample size was calculated by WHO sample size calculator, with confidence interval 95\%, and precision $5 \%$. Patients were selected by convenience sampling from outdoor clinics.
The Global Acne Grading Scale (GAGS) was used to grade acne as mild, moderate or severe. Mild acne (1-18) defined as predominance of comedones $(<20)$ or $<15$ inflammatory papules or a comedone / papule count $<30$ on face; moderate acne (19-30) when papules and pustules (15-50 lesions) with comedones and rarely cysts are present; severe acne (31-38 lesions) and very severe acne (> 39 lesions), ${ }^{10,11}$.

The disability caused by acne was assessed by Cardiff Acne disability index (CADI). Total score for all the five questions range from $0-15$ (score for each question 0-3). They were categorized as no impairment from acne (CADI 0), mild impairment (CADI 1-5), moderate impairment (CADI 6-10) and severe impairment (CADI 11-15) ${ }^{8}$.

SPSS version 17 was used to analyze data. Chi-square test applied for statistical association of various risk factors i.e. gender, obesity, grades of acne, socioeconomic class with grades of QoL impairment. $P$-value $<0.05$ considered to be statistically significant. Data presented as tables, pie chart and bar graphs.

\begin{tabular}{|c|c|c|c|}
\hline Questions & \multicolumn{2}{|l|}{ Score } & $n(\%)$ \\
\hline \multirow{4}{*}{$\begin{array}{l}\text { 1- Have u felt aggressive, frustrated, or embarrassed on account of your } \\
\text { acne? }\end{array}$} & Very much & 3 & $9(4.4 \%)$ \\
\hline & A lot & 2 & $48(23.4 \%)$ \\
\hline & A little & 1 & $114(55.6 \%)$ \\
\hline & Never & 0 & $34(16.6 \%)$ \\
\hline \multirow{4}{*}{$\begin{array}{l}\text { 2- Do you think acne has interfered with your social life and relationship } \\
\text { with the opposite sex? }\end{array}$} & Severely & 3 & $16(7.8 \%)$ \\
\hline & Moderately & 2 & $143(70 \%)$ \\
\hline & Occasionally & 1 & $10(4.9 \%)$ \\
\hline & Never & 0 & $36(17.6 \%)$ \\
\hline \multirow{4}{*}{$\begin{array}{l}\text { 3- Have you avoided wearing swimming costumes or clothes which may } \\
\text { expose areas of your trunk with acne? }\end{array}$} & Always & 3 & $65(31.7 \%)$ \\
\hline & Mostly & 2 & $17(8.3 \%)$ \\
\hline & Occasionally & 1 & $9(4.4 \%)$ \\
\hline & Never & 0 & $114(55.6 \%)$ \\
\hline \multirow{4}{*}{ 4- Have you been concerned about the appearance of your acne? } & Very depressed & 3 & $47(23 \%)$ \\
\hline & Usually concerned & 2 & $57(27.8 \%)$ \\
\hline & Occasionally concerned & 1 & $63(30.7 \%)$ \\
\hline & Never & 0 & $38(18.5 \%)$ \\
\hline \multirow{4}{*}{ 5- Does your acne pose a problem to you now? } & Worst & 3 & $54(26 \%)$ \\
\hline & Major problem & 2 & $76(37 \%)$ \\
\hline & Minor problem & 1 & $50(24.4 \%)$ \\
\hline & No problem & 0 & $25(12 \%)$ \\
\hline Grades of impairment & \multicolumn{2}{|c|}{ Range of CADI score } & $n(\%)$ \\
\hline No impairment & \multicolumn{2}{|l|}{0} & $15(7.3 \%)$ \\
\hline Mild impairment & \multicolumn{2}{|l|}{$1-5$} & $40(19.5 \%)$ \\
\hline Moderate impairment & \multicolumn{2}{|l|}{$6-10$} & $125(61 \%)$ \\
\hline Severe impairment & \multicolumn{2}{|l|}{$11-15$} & $25(12.2 \%)$ \\
\hline
\end{tabular}


Nadia Shams, Furquana Niaz, Sumayya Zeeshan, Sadaf Ahmed, Shazia Farhat, Naresh Kumar Seetlani

\section{RESULTS}

Among 205 cases of acne, there were 49(24\%) males and $156(76 \%)$ females. Mean age was 25+5.7 (14-36) years. As per GAGS score; 93(45.4\%) had mild acne, $90(44 \%)$ moderate acne, 17(8.35) severe acne and 5 $(2.4 \%)$ had very severe acne.

For acne induced QoL impairment by CADI score, there was no impairment (CADI=0) in 15(7.3\%), mild impairment (CADI=1-5) in 40(19.5\%), moderate impairment (CADI=6-10) in $125(61 \%)$ and severe impairment (CADI=11-15) in 25(12\%) (Table I). The severity of impairment was found to be significantly associated with gender, socioeconomic class, education, acne grade, obesity and use of alternative medicine $(p<0.05)$. Duration of acne was $<1$ year in $105(51 \%), 1-5$ years in $91(44 \%)$ and $>5$ years in 9 $(4.4 \%)$.

Regarding the individual questions of CADI score; 171 $(83 \%)$ patients responded that they felt aggressive, frustrated or embarrassed due to acne. 169(82\%) said that acne has somewhat affected their relation with opposite sex. 91(44\%) said that they avoided wearing clothes that may have exposed the affected areas of body other than face. 167(81\%) showed varying severity of concern for acne. Acne imposed a problem to varying extent in $180(88 \%)$ cases (Table I).

There were $147(72 \%)$ cases in adolescent age group

TABLE I: CARDIFF ACNE DISABILITY INDEX (CADI) FOR QOL IN ACNE $(n=205)$

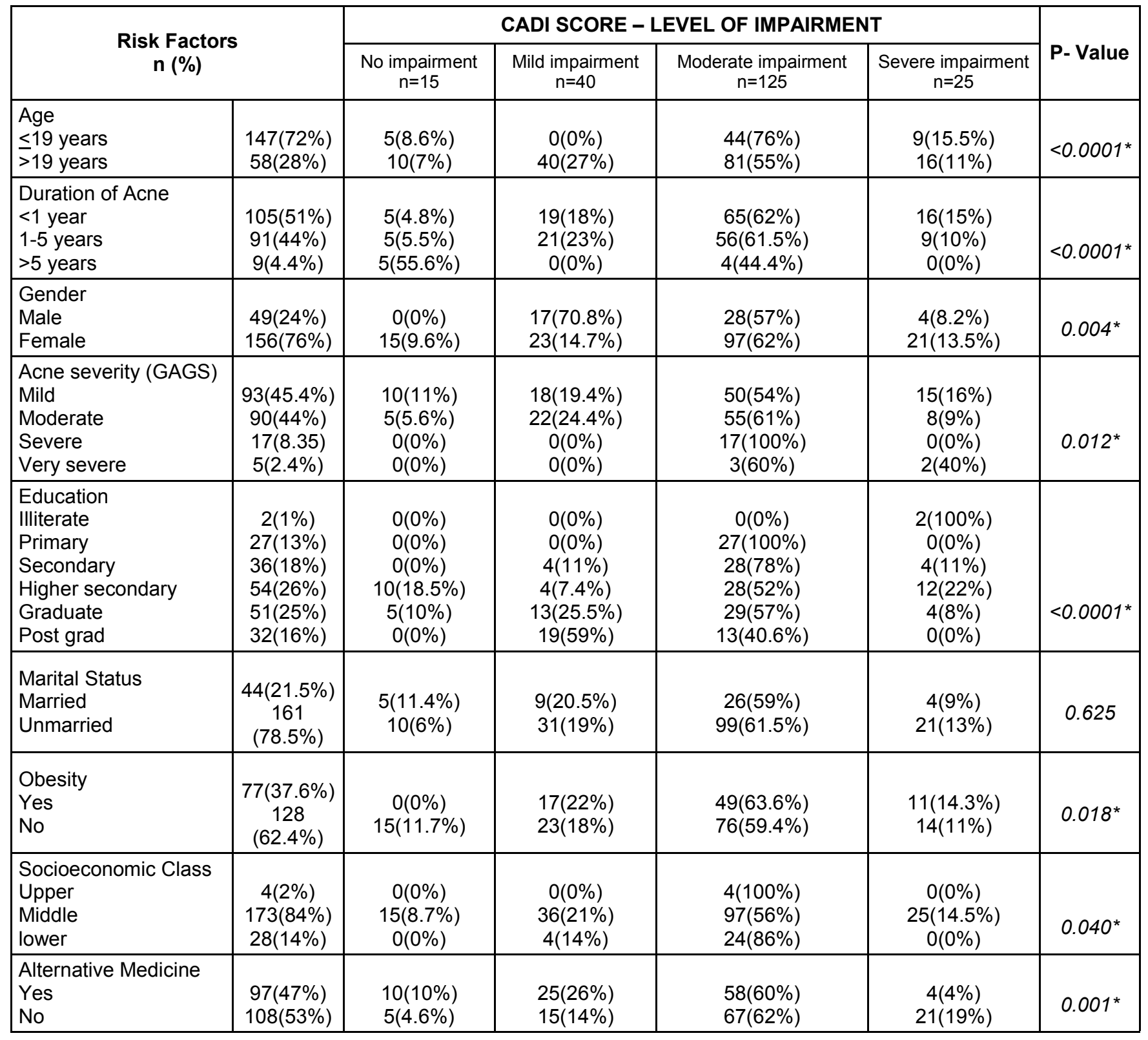


Cardiff Acne Disability Index based Quality of Life

TABLE II: CADI SCORE BASED LEVELS OF QOL IMPAIRMENT AND ASSOCIATED RISK FACTORS ( $\mathrm{n}=205)$

\begin{tabular}{|c|c|c|c|c|c|}
\hline $\begin{array}{c}\text { Severity of Acne } \\
\text { (GAGS) }\end{array}$ & $\begin{array}{c}\text { No } \\
\text { Impairment }\end{array}$ & $\begin{array}{c}\text { Mild } \\
\text { impairment }\end{array}$ & $\begin{array}{c}\text { Moderate } \\
\text { impairment }\end{array}$ & $\begin{array}{c}\text { Severe } \\
\text { impairment }\end{array}$ & \multirow{2}{*}{$p$-value } \\
\hline Mild & $10(11 \%)$ & $18(19.4 \%)$ & $50(54 \%)$ & $15(16 \%)$ & \\
\cline { 1 - 4 } Moderate & $5(5.6 \%)$ & $22(24.4 \%)$ & $55(61 \%)$ & $8(9 \%)$ & \multirow{2}{*}{$0.012^{*}$} \\
\cline { 1 - 4 } Severe & $0(0 \%)$ & $0(0 \%)$ & $17(100 \%)$ & $0(0 \%)$ & \\
\hline Very Severe & $0(0 \%)$ & $0(0 \%)$ & $3(60 \%)$ & $2(40 \%)$ & \\
\hline
\end{tabular}

(Test of significance; Chi-square test; "significant $p<0.05$ )

(i.e. $\leq 19$ years age) and $58(28 \%)$ above 19 years age. Higher levels of QoL impairment were observed in adolescent age group; i.e. moderate impairment in $76 \%$ (Vs. 55\% among $>19$ years age) and severe impairment in $15.5 \%$ (Vs. $11 \%$ among $>19$ years age) $(p<0.0001)$.

In view of gender, higher levels of QoL impairment were observed among females as compared to males; i.e. moderate impairment in $62 \%$ females (Vs. $57 \%$ males) and severe impairment in $13.5 \%$ females (Vs. $8.2 \%$ males $)(p=0.004)$.

Only $2(1 \%)$ cases were illiterate, $27(13 \%)$ had primary education, 36(18\%) had secondary education, 52 (26\%) had higher secondary education and $83(41 \%)$ were graduate and above. Education status was significantly associated with QoL impairment level $(p<0.0001)$.

There were $44(21.5 \%)$ cases married and $161(78.5 \%)$ cases unmarried. Marital status wasn't found to be associated with QoL impairment $(p=0.625)$. In relation to body mass index, almost $77(37.6 \%)$ cases were obese and 128(62.5\%) cases were non-obese. Obesity was found to be associated with higher levels of QoL impairment, i.e. mild impairment in $22 \%$ obese (Vs. $18 \%$ non-obese), moderate impairment in $63.6 \%$ obese (Vs.59.4\%) non-obese and severe impairment in $14.3 \%$ obese (Vs. $11 \%$ non-obese) $(p=0.018)$.

There were $97(47 \%)$ cases with history of practicing alternative medicine (that included hikmat, homeopathic and mud application); and 108(53\%) cases with no such history. As per socioeconomic class $28(14 \%)$ belong to lower class, $173(84 \%)$ middle class and $4(2 \%)$ upper socioeconomic class. Higher levels of QoL impairment were found in lower socioeconomic class $(p=0.040)$.

\section{DISCUSSION}

Acne vulgaris is a common skin disease frequently seen in adolescence. Literature proves not only the association of psychological morbidity with skin diseases, but also significant role of psychological interventions as an adjunct therapy. ${ }^{12}$ One third of the patients presenting to dermatology dept. are found to have significant psychological component in their presenting complaints. ${ }^{13}$ Ejaz et al in regional study conducted in Rawalpindi found impaired quality of life in chronic skin conditions. ${ }^{14}$ Similarly Bashir et al in Bahawalpur Pakistan found depression in $34 \%$ of dermatology cases. $^{15}$

Acne severity being assessed by GAGS score showed that vast majority of patients had mild to moderate acne and fewer had severe or very severe acne (figure l). Similar pattern was observed in

\section{FIGURE I: GRADES OF QUALITY OF LIFE IMPAIRMENT IN ACNE CASES ACCORDING TO CARDIFF ACNE DISABILITY INDEX (CADI) $(n=205)$}

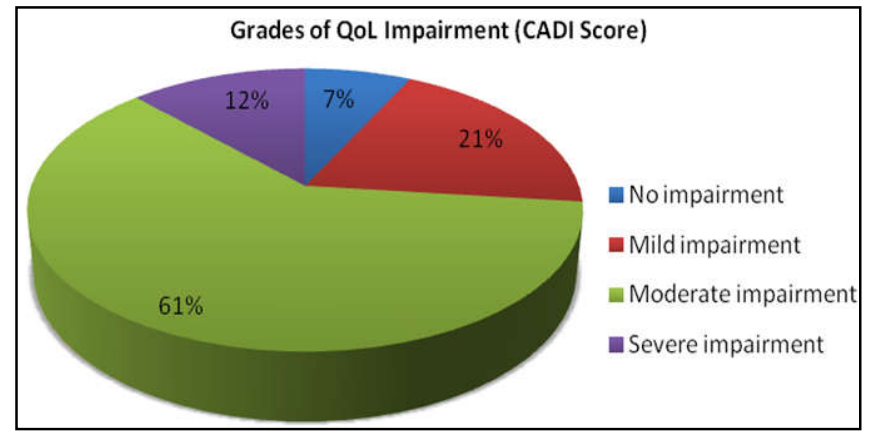

comparative studies by Yahya et $\mathrm{al}^{16}$ in Nigeria and Hanisah et al ${ }^{17}$ in Malaysia. They recorded $93 \%$ and $90 \%$ frequency of mild acne respectively. However Tan et $\mathrm{al}^{18}$ obtained a near equal prevalence of moderate to severe acne $(48.6 \%)$ and mild acne $(51.4 \%)$ in Singaporean adolescents. Among the hospital based studies, Kokandi et al ${ }^{19}$ found mild grade of acne in $73 \%$, moderate in $25 \%$ and severe in $1.8 \%$. Similarly Durai et al found $47 \%$ with mild acne, $38 \%$ with moderate, $14 \%$ with severe and $1 \%$ with very severe acne ${ }^{20}$.

In current study, there were more female cases, i.e. $76 \%$ females Vs. $24 \%$ males. Possible reason could be that this was hospital based study and predominantly females might be presenting in outdoor to seek help about their acne. Also it may reflect the regional predominance of acne among females. Contrary to this, international studies by Hanisah et 
$\mathrm{al}^{17}$ in Malaysians and Do JE et $\mathrm{al}^{21}$ in Korean adolescents claim that males are more prone to acne as compared to females. Other explanation for female predominance in our study include the frequent use of over the counter steroid containing creams for treatment of acne and other skin conditions, a practice which is common among females. Also the use of topical steroids for skin bleaching is common in our environment, more in females than males that has been associated with the development of steroid induced acne.

CADI score showed that $61 \%$ cases had moderate impairment and $19.5 \%$ had mild impairment. However fewer cases had no impairment in quality of life. Certain questions in the CADI questionnaire were observed to have more impact on our subjects than others (Table 1). Fewer cases $(31.7 \%)$ were affected by question 3 which alluded to the presence of acne on extra-facial areas and avoidance of clothes revealing the extra facial acne. This may either imply that extra-facial acne is uncommon in our subjects. Also as per the social norms and cultural beliefs in our country, majority of people (particularly females) prefer using covered clothes. This could be the possible reason for our findings. This was also observed in a study conducted in Malaysia ${ }^{17}$.

The high percentage of respondents with QoL impairment were found in question 4 and 5 (Table I), which revealed that $27.8 \%$ (question 4) were psychologically perturbed by appearance of their skin and $37 \%$ (question 5 ) thought that their acne was a problem. The question also elicited the high percentage of responses than study by Hanisah et $\mathrm{al}^{17}$ and Peric et $\mathrm{al}^{22}$ implying that these questions allowed for a greater degree of problems articulation than others.

On questioning about the acne related embarrassment or aggression, more than half of the respondents said that they had little embarrassment. However, in view of social life or relationship being affected by acne, $70 \%$ respondents said they had moderate impairment. Hence, suggesting that these domains don't impose a major issue to our subjects.

The higher grades of impairment were observed in adolescent age group (i.e. $<19$ years) as compared to older ones. Similarly those presenting with $<5$ years duration of acne had higher grades of impairment as compared to long standing cases. Hence, the impaired quality of life may lead to earlier presentation to seek help (Table II).

Female gender was associated with higher grades of impairment as compared to males. However, marital status wasn't found to be associated with impairment in QoL. Those cases of acne having obesity had higher grades of impairment as compared to non-obese. Thus, indicating that obesity could be an add-on factor which further impairs the QoL, self-esteem and confidence among those with acne. We may conclude that physician should expect higher grades of QoL impairment in acne cases that have obesity as a co-morbid.

The use of alternative medicine for management of acne was observed in almost half of the acne cases. This includes homeopathic, herbal and hikmat medications. This reflects the regional trend of alternative medicine use. Possible reasons for seeking such help could be financial constraints, lack of access to dermatological facility, being advised by the relatives or friends claiming cure by alternative medicine.

While studying the QoL with various grades of acne, the higher grades of acne were found to be associated with higher impairment of QoL. Among those with mild acne, almost half of the cases had moderate impairment. The figure rise to $60 \%$ (moderate impairment) in moderate acne cases and $100 \%$ in severe acne cases (figure II).

\section{FIGURE II: BAR GRAPH PRESENTATION OF QOL IMPAIRMENT (CARDIFF ACNE DISABILITY INDEX) AMONG VARIOUS GRADES OF ACNE (GAGS SCORE)}

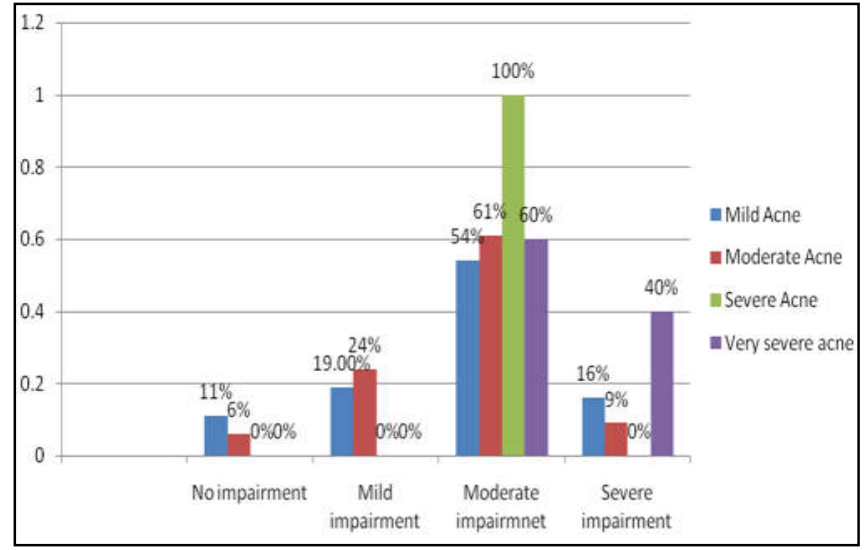

There is limited regional data available on quality of life in acne. The literature review shows studies being conducted in neighboring countries i.e. Iran and India ${ }^{20,23}$. Current study will be helpful to study the impairment in quality of life in our patients with acne and compare this data with regional and international literature. This may be helpful for dermatologists and general physicians dealing with acne cases.

Those with impaired quality of life may be counseled and suggested measures to enhance self-esteem and confidence while patient is undergoing the 
management. Also cases that need psychologist review or counseling may be managed in collaboration with the psychologist. Weight reduction, avoiding alternative therapy and regular counseling sessions may also improve QoL in acne cases. Results of current study may act as interface to enhance the tools for QoL assessment as well as measures to be taken in our high risk acne cases

\section{LIMITATIONS}

Current study has been conducted in a tertiary care hospital and results of this study should not be generalized. Authors suggest the need for further regional studies to validate the results.

\section{CONCLUSION}

Acne vulgaris affects Qol among adolescents to varying degrees. Severity of acne grade, female gender, obesity, low education status and poverty are the suggested risk factors for impaired QoL among acne cases. Early identification of acne cases at risk of impaired Qol may help us to take QoL intervention measures like counseling and psychologist review in addition to medical management. This may improve the social and psychological wellbeing of acne cases.

\section{REFERENCES}

1. Hazarika N, Archana M. The Psychosocial Impact of Acne Vulgaris. Indian J Dermatol. 2016; 61 (5):515-520.

2. Hay RJ, Johns NE, Williams HC, et al. The global burden of skin disease in 2010: an analysis of the prevalence and impact of skin conditions. J Invest Dermatol. 2014; 134(6):1527-34.

3. Morrison I, Löken LS, Olausson H. The skin as a social organ. Exp Brain Res. 2010; 204(3):305-14.

4. Demircay Z, Seckin D, Senol A, Demir F. Patient's perspective: an important issue not to be overlooked in assessing acne severity. Eur $\mathrm{J}$ Dermatol. 2008; 18:181-4.

5. Ahmed S, Ahmed I. Frequency and magnitude of anxiety and depression among acne patients: a study of 100 cases. JLUMHS. 2007; 6(1):25-29.

6. Jones-Caballero M, Chren MM, Soler B, Pedrosa E, Penas PF. Quality of life in mild to moderate acne: Relationship to clinical severity and factors influencing change with treatment. JEADV. 2007; 21:219-26.

7. World Health Organization. Division of Mental Health and Prevention of Substance Abuse. (1997). WHO QOL: Measuring Quality of Life. Geneva: World Health Organization.
Available from http://www.who.int/iris/ handle/10665/63482

8. Motley RJ, Finlay AY. Practical use of a disability index in the routine management of acne. Clin Exp Dermatol. 1992; 17(1):1-3.

9. Tidman MJ. Prompt treatment of acne improves quality of life. Practitioner. 2012; 256(1752): 1517.

10. Allen BS, Smith G Jr. Various parameters for grading acne vulgaris. Arch Dermatol. 1982; 118 (1): 23-25.

11. Hacivelioglu S, Gungor AN, Gencer M, et al. Acne severity and the Global Acne Grading System in polycystic ovary syndrome. Int $\mathrm{J}$ Gynecol Obstet. 2013; 123(1):33-36.

12. Magin P, Sibbritt D, Bailay K. The Relationship Between Psychiatric Illnesses and Skin Disease; A Longitudinal Analysis of Young Australian Women. Arch Dermatol. 2009; 145(8):896-902.

13. Ahmed AE, Al-Dahmash AM, Al-Boqami QT, Al-Tebainawi YF. Depression anxiety and stress among Saudi Arabian dermatology patients: cross -sectional study. Sultan Qaboos Univ Med J. 2016; 16(2):e217-23.

14. Ejaz A, Rao SE, Manzoor A, Niaz A. Quality of life assessment in chronic skin disorders. JPAD 2015; 25(2):86-89.

15. Bashir K, Dar NR, Rao SU. Depression in Adult Dermatology Outpatients. JCPSP. 2010; 20(12): 811-13.

16. Yahya $\mathrm{H}$. Acne vulgaris in Nigerian adolescents Prevalence, severity, beliefs, perceptions, and practices. Int J Dermatol. 2009; 48(5):498-505.

17. Hanisah A, Omar K, Shah SA. Prevalence of acne and its impact on the quality of life in school-aged adolescents in Malaysia. J Prim Health Care. 2009; 1(1):20-25.

18. Tan $\mathrm{HH}$, Tan AW, Barkham T, Yan XY, Zhu M. Community-based study of acne vulgaris in adolescents in Singapore. $\mathrm{Br} J$ Dermatol. 2007 Sep; 157(3):547-51.

19. Kokandi A. Evaluation of acne quality of life and clinical severity in acne female adults. Dermatol Res Pract . 2010; 2010:410809.

20. Durai PC, Nair DG. Acne Vulgaris and Quality of Life Among Young Adults in South India. Indian J Dermatol. 2015; 60(1):33-40.

21. Do JE, Cho S, In S, Lim K, Lee S, Lee E. Psychosocial aspects of Acne vulgaris: a community-based study with Korean adolescents. Ann Dermatol. 2009; 21(2): 125-129. 
22. Peric J, Maksimovic N, Jankovic J, Mijovic B, Reljic V, Jankovic S. Prevalence and quality of life in high school pupils with acne in Serbia. Vojnosanit Pregl. 2013; 70(10):935-39.
23. Norbala MT, Mozaffary $B$, Noorbala $M$. Prevalence of acne and its impact on the quality of life in high school-aged adolescents in Yazd, Iran. JPAD. 2013; 23(2):168-72.

AUTHOR AFFILIATION:

Dr. Nadia Shams (Corresponding Author)

Associate Professor, Department of Medicine

Rawal Institute of Health Sciences

Islamabad-Pakistan.

Email: nadia_shams@yahoo.com

Dr. Furquana Niaz

Assistant Professor, Department of Dermatology

Shaheed Mohtarma Benazeer Bhutto Medical College

Karachi, Sindh-Pakistan.

Dr. Sumayya Zeeshan

Senior Registrar, Department of Dermatology

Rawal Institute of health Sciences, Islamabad-Pakistan.

Dr. Sadaf Ahmed

Assistant Professor, Department of Dermatology

DIMC, OJHA Campus, Karachi, Sindh-Pakistan.

Dr. Shazia Farhat

Medical Specialist

Airport Security Hospital Karachi, Sindh-Pakistan.

Dr. Naresh Kumar Seetlani

Associate Professor of Medicine

Civil Hospital Karachi, Sindh-Pakistan. 